\section{ON THE CRYSTALLISATION OF SILVER, GOLD, AND OTHER METALS*}

THERE are few chemical experiments so well known as the growth of the "lead tree" a specimen of which is on the table, together with a "silver tree" that is said to have been made by the late Professor Faraday. These carry our minds back to the time of the alchemists, who called the first "arbor Saturni," and the second "arbor Dianæ ;" and they may be looked upon as the types of a large number of phenomena, in which the salt of one metal in solution is decomposed by some other metal. My assistant, Mr. Tribe, and myself have been lately ex-

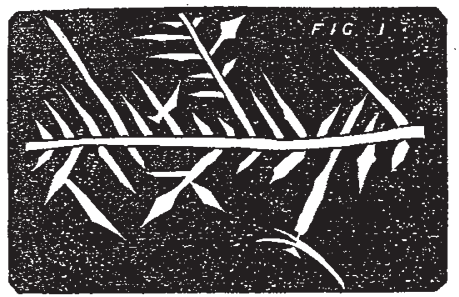

amining these replacements, the metallic crystals which are thus produced, and the forces that act through the liquid.

Our more special attention has been given to the mutual action of copper and nitrate of silver. If these two substances be brought into contact by the intervention of water, thare grow upon the red metal what may be well

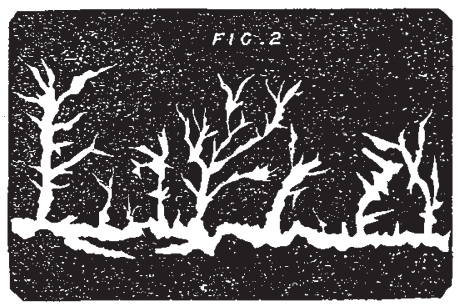

called "trces," and though the analogy between crysta's and plants is a very superficial one, yet the resemblances of external form are striking evough, and a nomenclature drawn from the garden seems the most expressive.

It is very beautiful to watch the growth of these silver crystals round a piece of copper under the microscope; a blue glass underneath adds to the effect, and they are

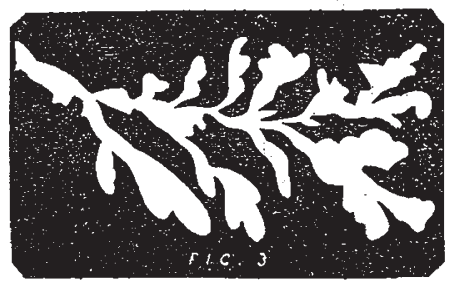

best seen when they reflect a strong light thrown upon them. They may also be thrown upon a screen as opaque objects, but the beauty and lustre of their surface is in this way lost.

The crystals of silver thus produced differ both in colour and form, according to the strength of the solution. If it be very weak, say one per cent, the copper is fringed with black bushes of the metal, which, in growing, change their colour to white without any alteration of crystalline * Lecture delivcred at the Royal Institution of Great Britain, February
$16,187_{2}$, by John Hall Gladstone, F.R.S. form that can be detected by a powerful microscope. A stronger solution gives white crystals from the commencement, which frequently assume the appearance of fernleaves; while the growth from a still stronger liquid reminds us rather of a furze bush. If the nitrate of silver amount to 15 per cent., or thereabouts, there occurs a steady advance of brilliantly white moss; and if the solution be saturated, or nearly so, say 40 per cent., this moss is very sturdy, often ending in solid crystalline knobs, or strretching out into the liquid as an arborescent fringe.

In all these cases, however, when the solution in front of the growing crystals has been somewhat exhausted, certain prominent or well-circunstanced crystals seem to

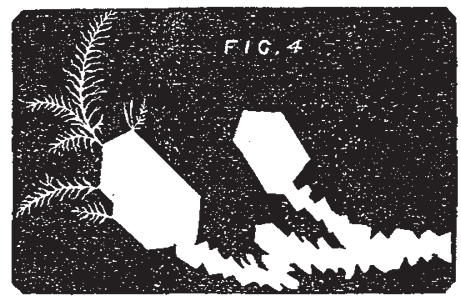

monopolise the power, and to push forward through the remaining portions of the liquid. This gives rise to beautiful branches which assume a variety of graceful forms, which it is hopeless to attempt to pourtray by diagrams, but of which the subjoined figures give some of the more characteristic outlines greatly magnified. The weak solutions produce feathery crystals somewhat as in

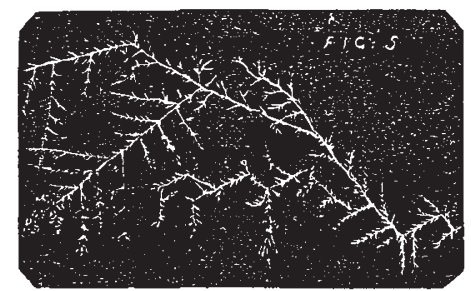

Fig. I, consisting of a straight central stem from which grow on either side crystalline rays that terminate in a sharp point, and frequently become themselves the centre stems of a similar.crystalline structure. In the outlying growth of a moderately strong solution the apparent regularity of the crystalline form is lost ; the main stem is built up of a confused mass of hexagonal plates, while

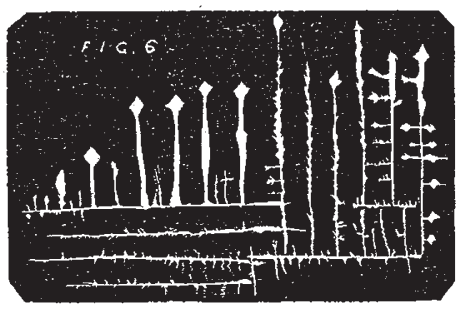

the side branches are an agglomeration of minute pointed crystals turning in every direction, and producing such jagged outlines as are drawn in Fig. 2. In stronger solutions still the branches lose every appearance of straightness, and they are built up of hexagonal plates so studded with crystalline specks that the whole has the rounded appearance depicted in Fig. 3. The arborescent crystals that succeed the fringes from a saturated solution, are smaller in their foliage than the last, and end in little spherical or botryoidal knobs. 
Beside these various forms, there occur all kinds of crystalline combinations, as, for instance, the spray sketched in Fig. 4, where the rough branches have terminated each in a large hexagonal plate, and the flowing past of a weakened solution has afterwards caused the growth of delicate fern-leaves. Often, too, a large expansion will take place in every direction, though joined to the parent stem by an almost invisible thread; or from the point of a long crystal there will branch out to right and left crescent-shaped structures, a process the com- mencement of which is seen in one of the side rays of Fig. I. The last traces of silver in the liquid will frequently give rise to delicate crystalline filaments wandering over the surface of the glass, as in Fig. 5.

If a piece of zinc be placed in a solution of neutral terchloride of gold, containing 9 per cent. of salt, there is an immediate outgrowth of black gold, which speedily changes to an advancing mass of yellow or perhaps lilac metal in lichen-like forms, from which proceed beautiful fringes of yellow or black, ending generally in such

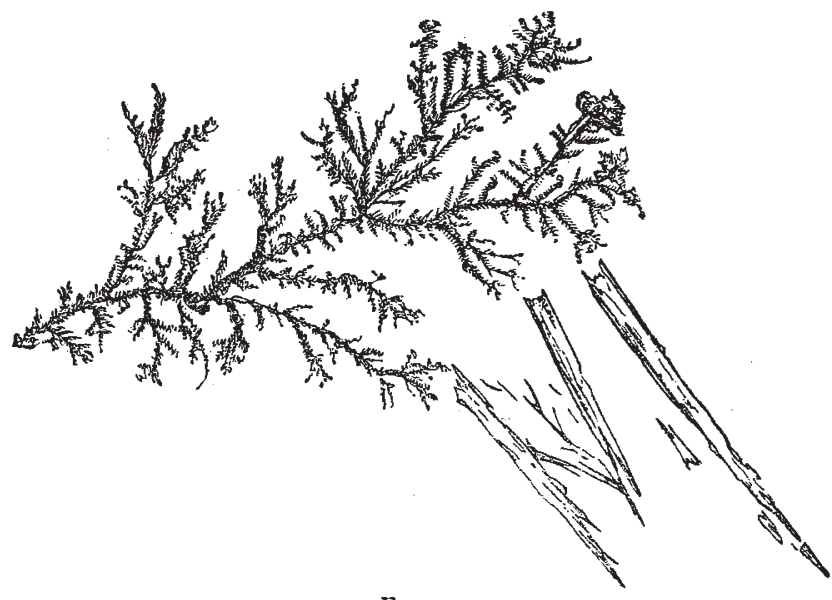

FIG 7

arborescent forms as are represented in Fig. 7. As these branches push into the yellow liquid, it becomes colourless even in advance of their points, and it frequently happens that yellow crystals of some salt shoot out in front of the crystallising metal, which follows them and builds up its advancing fronds at their expense. This is shown in the figure. The gold will generally shoot its yellow branches rapidly round the margin of the drop. Such a running branch has been seen to stop on touching at one point a loose piece of gold, which immediately in its turn became active, and commenced t. sprout on its farther side. Copper salts give round nodules, which have no crystalline appearance when deposited from moderately weak solutions, but a very stron $y$ solution of the chloride-xbout 40 per cent.-yields with zinc first a black thick growth, then arborescent fringes of red metal, termina:ing in cry;tals of very appreciable size:

The fringes referred to in the case of these three metals are still more characteristically developed by bismuth. When a solution of terchloride of bismuth acts on zinc,

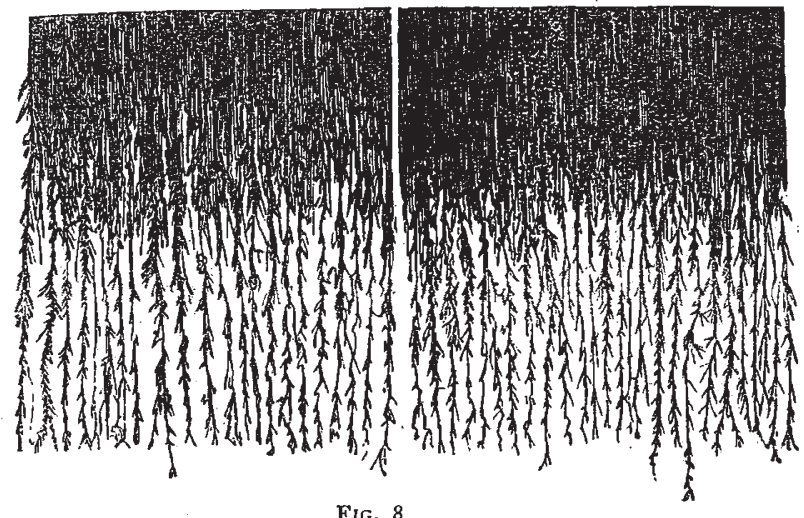

there is an immediate outgrowth of black fringes, such as Fig. 8, where they are seen on an illuminated field. These, as they advance, become more and more arborescent, and as the crystalline character develops itself more they change from black to grey. Sometimes bismuth presents itself in botryoidal masses, but the tendency to form these fringes is very strong.

Chloride of antimony with zinc also gives these black fringes, Lead salts yield crystals resembling those of silver; but leaves of irregular hexagonal plates prevail, and often grow to a large size. A solution of acetate of thallium, containing 20 per cent. of salt, quickly gives a beautiful forest of thorny crystals. Sulphate of cadmium gives rise to a small leaf-like growth on zinc; but a strong solution of chloride produces an appearance of sticks covered with small spines or knobs. The new metal indium is thrown down upon zinc in the form of thick white crystals. The deposition is promoted by touching the zinc with a piece of iron.

Tin gives beautiful results. If zinc be placed in a solu- 
tion of stannous chloride, it is quickly surrounded with an outgrowth of prolonged octohedra, and as these advance into the liquid it is easy to observe that the additions of new metal commence at the apex, and that the wave of chemical change proceeds down the lateral edge, occupying some seconds of time in depositing the new layer of material. Frequently, also, there is a luxuriant growth of large flat leaflets, or of symmetrical structures resembling fern-leaves, but with the fronds arranged at right angles, or combinations of these with octohedra, as shown in Fig. 6. These fern-leaves often begin of a dull grey colour ; but, as they advance, suddenly change to a brilliant white.

The particular form of these crystalline growths depends, therefore, primarily, on the specific character of the metal ; but this is greatly modified by the strength of the solution.

The forms assumed by native metals resemble those produced by this process of substitution. In some cases, indeed, it seems almost certain that the deposition of these minerals was effected in the same way, as, for instance, the silver which occurs sometimes in tufts, sometimes in large crystals, on the native copper of the Lake Superior district. Gold is frequently found in cubes more or less rolled, but the leaf gold from Transylvania bears a striking likeness to the crystals that form in our laboratory experiments. Silver is often found native as twisted hairs or wires of metal-a form that never occurs in the decomposition of its nitrate by copper, but which can be artificially produced in another way.

There has been noticed a singular tendency in old silver ornaments and coins to become crystalline and friable. Here is an ancient fibula from the island of Cyprus, supposed to be at least 1,500 years old, which, through the greater portion of its substance, presents a fracture something like that of cast-iron, and its specific gravity has been reduced in round numbers from Io to 9 . It contains a little copper. This property of certain metals or their alloys to change in condition and volume, is worthy the attention of those whose duty it is to make our standards. Experiments should be instituted for the purpose of learning what metals or combinations of metals are least subject to this secular change.

'These metallic crystals are Nature's first attempt at building. This material is the simplest possible-in fact, what chemists look upon as elementary. But how is the building carried on? What are the tools employed? Where are the bearers of burdens that bring the prepared pieces and lay them together according to the plan of the Great Architect? We must try to imagine what is taking place in the transparent solution. The silver, of course, existed at first in combination with the nitric element, and for every particle of silver deposited on the growing tree, an equivalent particle of copper is dissolved from the surface of the plate. The nitric element never ceases to be in combination with a metal, but is transferred from the one metal to the other. On the "Polarisation Theory," the positive and negative elements of the salt constantly change places and enter into fresh combinations, one consequence of which would be a gradual passage of the nitric element from the growing silver to the copper plate. This actually takes place, and there is a diminution of the salt at the ends of the silver branches, giving rise to an upward current, and a condensation of nitrate of copper against the copper plate, which gives rise to a strong downward current. These two currents are seen in every reaction of this nature. In the case of silver and copper, however, it has been proved that the crowding of the salt towards the copper plate is more rapid than would follow from the usual polarisation theory. The instrument employed for determining this point was a divided cell in which two plates, one of silver and the other of copper, connected together by a wire, are immersed each in a solution of its own nitrate, contained in each division of the cell, and separated from one another merely by parchment paper. The crystals of silver deposited on the silver plate in this experiment are very brilliant.

There are other indications of the liquid being put into a special condition by the presence of the two metals which touch one another. Thus zinc alone is incapable of decomposing pure water; but if copper or platinum be deposited on the zinc in such a manner that the water can have free access to the junction of the two metals, a decomposition is effected; oxide of zinc is formed, and hydrogen gas is evolved. At the ordinary temperature the bubbles of gas rise slowly through the liquid, but if the whole be placed in a flask and heated pure hydrogen is given off in large quantity. We have also found that iron or lead similarly brought into intimate union with a more electro-negative metal, and well washed, will decompose pure water.

As might be expected, the action of magnesium on water may be greatly enhanced by this method; and a pretty and instructive experiment may be made by placing a coil of magnesium in pure water at the ordinary temperature, when there will be scarcely any effect visible, and then adding a solution of sulphate of copper. The magnesium is instantly covered with a growth of the other metal, and at the same time the liquid seems to boil with the rapid evolution of hydrogen bubbles from the decomposed water.

When, however, the force of the two metals in contact has to traverse a layer of water, the resistance offered by the fluid prevents its decomposition. This must also be an important element in the decomposition of a metallic salt dissolved in water, and in fact we have found that the addition of some neutral salt, such as nitrate of potassium, increases the action-apparently by diminishing the resistance of the liquid. If, too, we increase the quantity of the dissolved metallic salt, we get more than a proportional increase of deposited metal. Thus, in an experiment made with the different strengths of nitrate of silver on the table, the following results were obtained in ten minutes, all the circumstances being the same except the strength of the solution :-
I per cent. solution dissolved $025 \mathrm{grm}$. copper.
$2 "$ " 2

$$
2
$$

In fact it has been found that" in solutions not exceeding 5 per cent., twice the amount of nitrate of silver dissolved in water gives three times the amount of chemical action; and this is true with other metals also in weak solution. It may be that this is not the precise expression of a physical law, but it agrees at least very closely with the results of experiment.

The power arising from this action of two metals on a binary liquid may be carried to a distance and produce similar decompositions there. This is ordinary electrolysis. Metals have often been crystalilised from their solutions in this way, and Mr. Braham has made excellent preparations of crystalline silver, gold, copper, tin, platinum, \&c., by using poles of the same metal as that intended to be deposited upon them. The forms thus obtained are precisely analogous to those produced by the simple immersion of one metal into the soluble salt of another, and illustrate still further the essential unity of the force that originates the two classes of phenomena.

\section{NOTES}

THE speech of the Prime Minister at the meeting held last week in support of the fund to pay off the debt at King's College was a striking comment on some recent utterances of members of the Government to the effect that Science is well able to support itself, and needs no assistance from the State. The claims of this fund on public assistance were earnestly and 